Focussed on "Crack Paths"

\title{
Experimental characterization of fiber-reinforced cementitious mortar under tension
}

\author{
P. Bernardi, R. Cerioni, D. Ferretti, F. Leurini, E. Michelini \\ Dept. of Engineering and Architecture, University of Parma (Italy) \\ patrizia.bernardi@unipr.it,.bttp://orcid.org/0000-0003-0554-5870 \\ roberto.cerioni@unipr.it,http://orcid.org/0000-0002-7873-4077 \\ daniele.ferretti@unipr.it, bttp:/ /orcid.org/0000-0001-6943-0488 \\ filippo.leurini@outlook.it \\ elena.michelini@unipr.it, bttp:/ / orcid.org/0000-0002-2262-0740
}

\begin{abstract}
This work focuses on the mechanical characterization of the inorganic matrix used for Fiber-Reinforced Cementitious Matrix (FRCM) composites, nowadays widely used to retrofit existing reinforced concrete and masonry structures. While several works in technical literature investigate the experimental behavior of the whole FRCM composite, few information are available on the mechanical characterization of the mortar, which contains polymers and synthetic fibers in its admixture. However, the knowledge of its behavior in tension, especially after crack formation, is an important feature for the calibration of constitutive models to be adopted in the study of structural elements strengthened with FRCM. To this aim, an experimental program was performed on mortar specimens characterized by different shapes and dimensions, tested under direct tension or three-point-bending. From the performed tests, it was possible to characterize inorganic matrix behavior both in the uncracked stage, through the determination of the elastic parameters (elastic modulus and Poisson's coefficient), and in the cracked stage. The use of digital image correlation (DIC) technique also allowed the study of the evolution of crack propagation in the specimens. Lastly, a correlation factor between axial and flexural tensile strength is proposed, for both design and numerical modelling purposes.
\end{abstract}

KEYWORDS. FRCM composites; Inorganic matrix; Direct tensile test; Bending test; Digital Image Correlation.

\section{OPEN ACCESS}

Citation: Bernardi, P., Cerioni, R., Ferretti, D., Leurini, F., Michelini, E., Experimental characterization of fiber-reinforced cementitious mortar under tension, Frattura ed Integrità Strutturale, 48 (2019) 97-104.

Received: 30.11 .2018

Accepted: 01.01.2019

Published: 01.04.2019

Copyright: (C) 2019 This is an open access article under the terms of the CC-BY 4.0, which permits unrestricted use, distribution, and reproduction in any medium, provided the original author and source are credited.

\section{INTRODUCTION}

I n recent years, Fibre Reinforced Cementitious Matrix (FRCM) composites gained an increasing attention as a sustainable methodology to retrofit existing masonry and reinforced concrete structures. They are constituted of a dry fibre fabric or mesh that is anchored to an existing support through a cement-based adhesive. This latter is typically 
made of combinations of Portland cement, silica fume and fly ash as the binder, with the addition of a low dosage (less than $5 \%$ by weight) of dry polymers in the mix. The use of an inorganic matrix guarantees many advantages [1], since it is easy to prepare as any hydraulic product, it is not toxic for the workers and for the environment and it can be applied even on irregular surfaces. Moreover, it maintains its properties up to high temperatures and is not combustible, providing a good reaction to fire like the concrete substrate, and it can be applied also over a damp substrate, since humidity promotes adhesion to the hydraulic matrix.

Although in recent years the experimentation on the whole FRCM systems is increased, both on the composite material under tension [2] or on FRCM-concrete joints [3], and on strengthened RC beams [4, 5], only few experimental information can be found for the characterization of the inorganic matrix. Manufacturers' data sheets generally provide minimum values of its compressive and bending strength and of the secant modulus of elasticity. However, numerical modelling requires refined laws able to describe the actual behaviour of the component materials, and while for the fibre fabric a linear elastic behaviour can be generally accepted, because of the high strength and stiffness of the material, for the inorganic matrix the influence of its post-cracking behaviour on the global response is significant and must be determined.

This work is focused on the investigation of mortar's mechanical properties by performing two different tests: direct tension and three-point-bending tests. As known [6, 7], among tensile tests, direct tension is quite demanding, because the localised actions of the grips, the presence of geometrical imperfections of the specimens as well as the kinematics of the end restraints may have a great influence on the results. Therefore, three-point-bending tests, which are recognized to be less affected by uncertainties, can help to provide a more efficient material characterization. Moreover, while for normal concrete the conversion factor between axial and flexural tensile strength can be deduced for a given beam depth from fracture mechanics considerations [8], a possible correlation for this kind of mortar is not available in scientific literature. However, for numerical modelling, this conversion factor is in many cases necessary to calibrate constitutive laws to implement into numerical models $[9,10]$, if only flexural tensile strength is available.

(a)
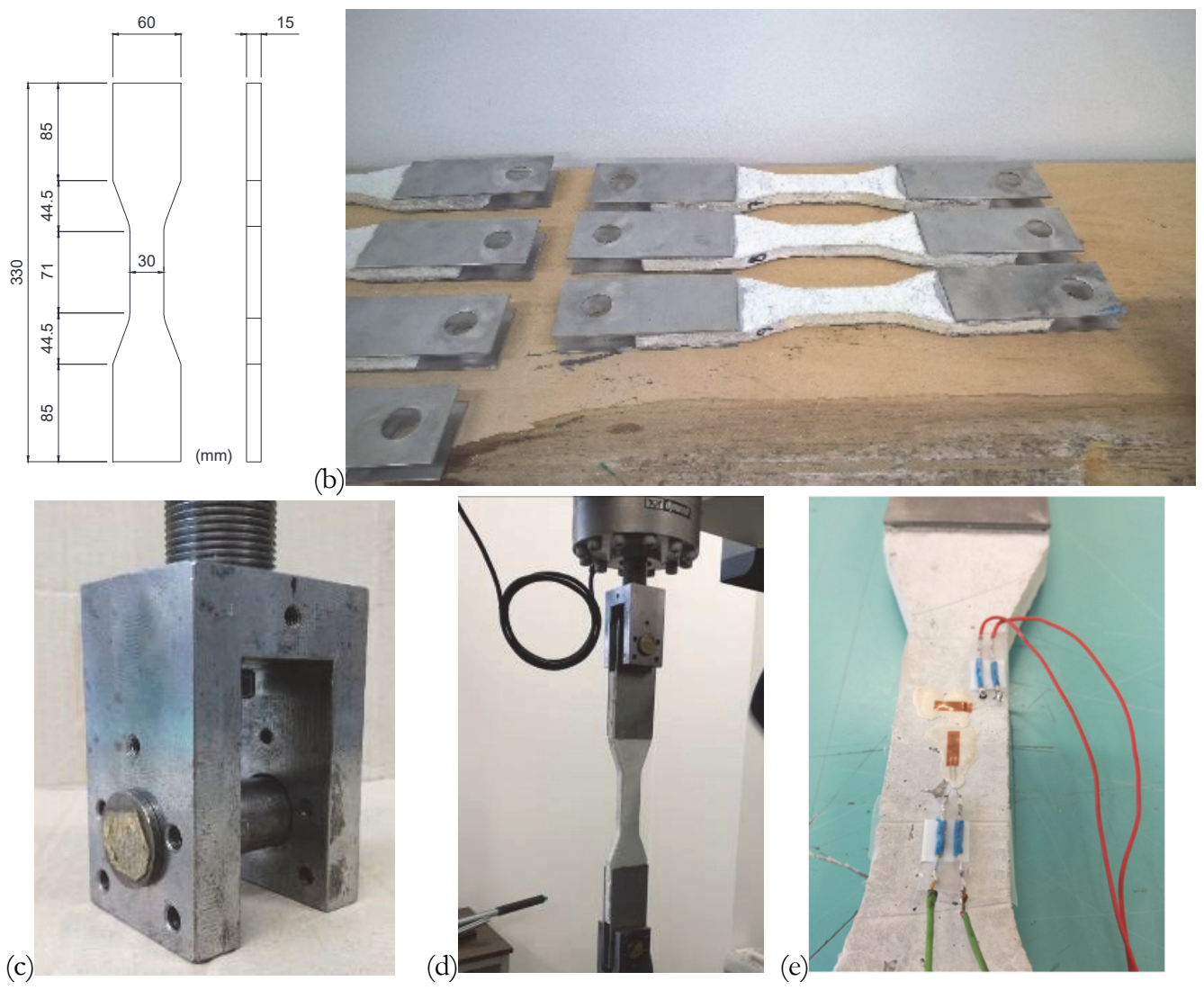

Figure 1: (a) Adopted dimensions for dog-bone specimens; (b) steel plates bonding; (c) adopted grip type and (d) direct tension test setup; (e) strain gauges bonding (only for 3 specimens of the $2^{\text {nd }}$ series). 


\section{EXPERIMENTAL TESTING}

$\mathrm{E}$ xperimentation was aimed to the material characterization (in terms of tensile strength, elastic modulus and Poisson's coefficient) of the inorganic matrix layer adopted for FRCM composites. A commercially available stabilised cementitious mortar with dispersed short (approximately $5 \mathrm{~mm}$ ) polypropylene fibres was considered for testing. This mortar is usually adopted for FRCM systems tailored for reinforced concrete structures and is characterised by a specific weight (referred to fresh mortar) equal to $1.80 \pm 0.05 \mathrm{~g} / \mathrm{cc}$ and by a consistency of $175 \mathrm{~mm}$ according to EN 13395-1.

\section{Specimen dimensions and preparation}

Mortar mixing was carried out according to manufacturer's instructions by adopting a drill paint mixer. Mixing ratio was 6.5 1 of water for $25 \mathrm{~kg}$ of mortar.

For direct tensile tests, dog-bone specimens $15 \mathrm{~mm}$ thick were used (Fig. 1). The dimensions were determined according to Japanese Standard [11] for cement-based composites with short fibres HPFRCC (High Performance Fibre Reinforced Cement Composites with Multiple Fine Cracks), since these composites are characterised by high ductility and fine aggregates, so resulting in a macroscopic behaviour quite similar to that of the investigated mortar. Two experimental campaigns were performed, casting eight specimens in the first one and nine in the second one.

As regards bending tests, prismatic samples 40x40x160 mm were used (Fig. 2), according to standard EN 1015-11 for masonry-hardened mortar [12]. Moreover, a central, $3 \mathrm{~mm}$ deep notch was cut in order to localize the crack within the knifeedges of the clip-gauge that controls the test. Three specimens were cast in the first campaign, while four in the second one. In the following, each specimen is designated through the symbols $\mathrm{T}$ or $\mathrm{B}$ (traction or bending) - followed by the number 1 or 2 (first or second series) and by the progressive specimen number. The specimens were cured for 28 days at laboratory conditions before testing.
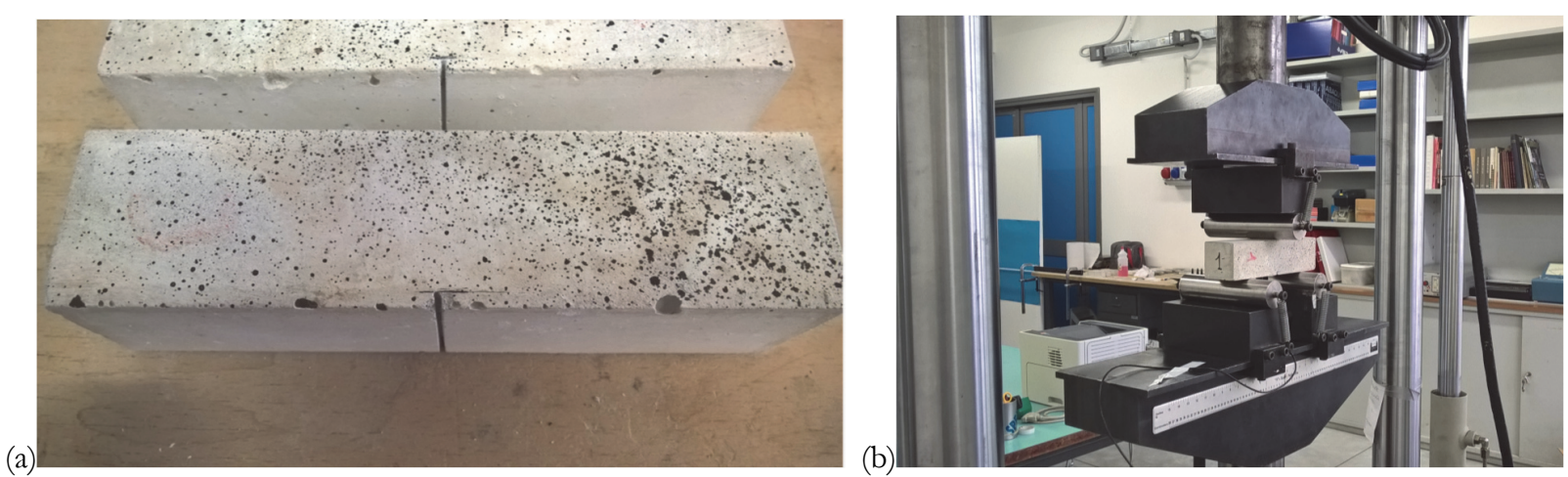

Figure 2: (a) Prismatic specimens; (b) three-point-bending test setup.

\section{Test setup}

Experimental tests were performed under displacement control by using a digitally controlled Instron 8862 Universal Testing Machine $(10 \mathrm{kN})$.

For direct tensile tests, among the several gripping mechanisms that have been developed for uniaxial testing, a Clevis grip was adopted, so applying the axial load by means of shear stresses to the specimen. To this aim, two holed steel plates were glued at each end of the specimens (Fig. 1b) to allow the grip of the testing machine, achieved through a properly designed grip system (Fig. 1c-d). One transversal and two longitudinal $10 \mathrm{~mm}$ strain gauges were applied on the opposite sides of three specimens belonging to the second series of tests, for the measure of axial and transversal strains before cracking (Fig. 1e).

Specimens under three-point bending were tested under crack mouth opening displacement (CMOD) control, by setting a clip gauge across the notch (Fig. 3a). The specimens were simply supported over two rollers, providing a net span of 100 $\mathrm{mm}$, while an upper roller was placed as contrast for the application of the load (Figs. 2b, 3).

During test execution, Digital Image Correlation (DIC) technique was adopted to complete the measurement acquisition in terms of displacements, strains and crack pattern. As known, in recent years DIC has become a powerful tool for material characterization, above all when the behavior is affected by cracking occurrence, as in cement-based matrices used for composites [13]. The specimen surface was smoothed and a speckle pattern, consisting of randomly distributed black dots over a white background was realized by means of spray-painting (Figs. 3, 4). A high-resolution camera (Nikon D750, 24.3 
Megapixel full frame) was used and placed on a stiff frame, and stable lighting conditions were guaranteed. Digital images were taken at a constant time interval of 10s. The sequence of digital images was processed by means of the software program Ncorr [14], developed in MATLAB environment. DIC was applied to the first series of direct tension tests and to both the performed series of bending tests.

(a)

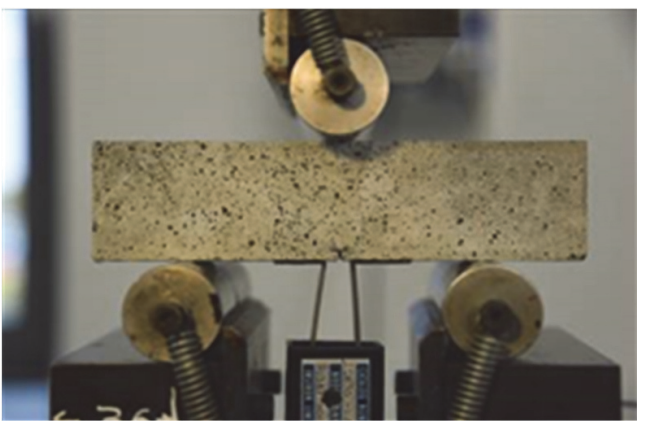

(b)

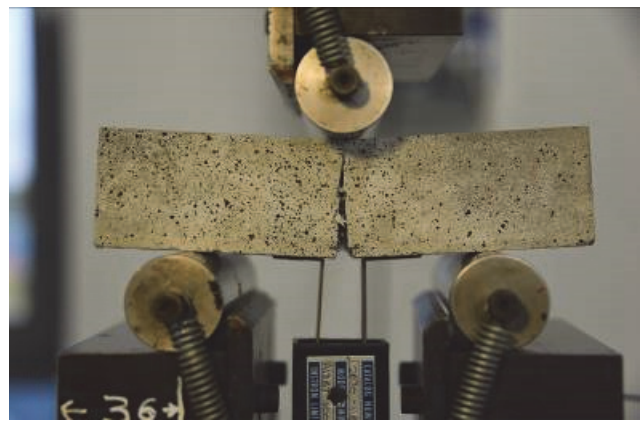

Figure 3: (a) Three-point-bending test under CMOD control; (b) typical failure of a prismatic sample under bending.

\section{Direct tensile tests}

Dog-bone specimen shape determined the development of cracking within the central zone, characterized by a reduced size (Fig. 4). First cracking occurs immediately at the reaching of mortar tensile strength; subsequently the specimen can still bear load, even if reduced, thanks to the random presence of dispersed fibres, which allow cracking development until high crack opening values (Fig. 5a). The resulting stress - longitudinal displacement response of series 1 specimens under direct tension is plotted in Fig. 5b. The stress is determined by dividing the load provided by INSTRON machine by the effective value of the specimen cross-section area. Since two of the tested specimens showed an anomalous behavior, with the development of cracks outside their central zone (see the crack path of specimens T-1-7 and T-1-8 in Fig. 4), these were discarded from the analysis of the results.
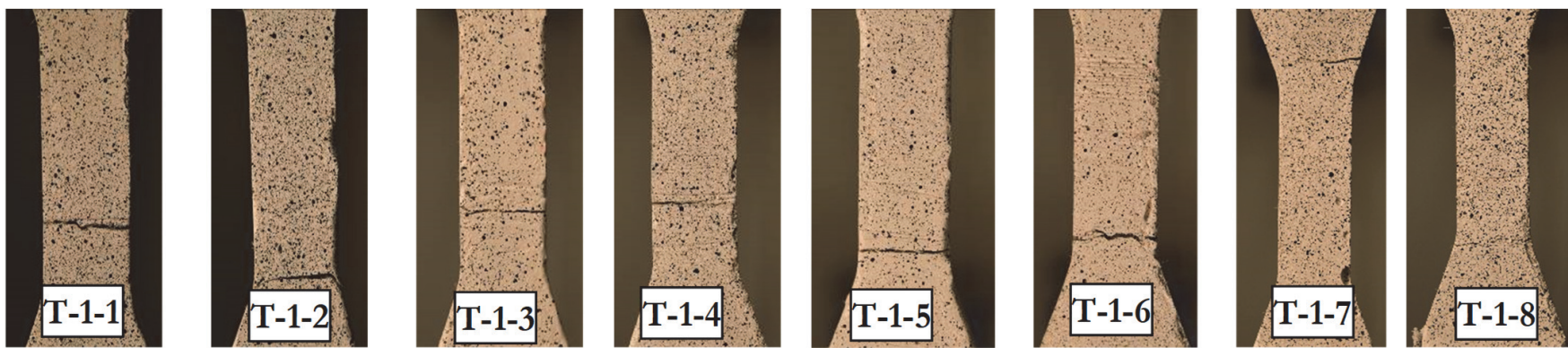

Figure 4: Crack pattern at the end of the test for series 1 specimens (specimens T-1-7 and T-1-8 were discarded from analysis).

The obtained values of the axial tensile strength are also summarized in Tab. 1, while Tab. 2 refers to the specimens of the second series. As can be seen, a mean value of tensile strength of $1.77 \mathrm{MPa}$ and $2.08 \mathrm{MPa}$ was found respectively for the specimens of the first and the second series. By considering the cracking loads from all the two series of performed tests, a mean value of tensile strength of $1.95 \mathrm{MPa}$ with a standard deviation of $0.45 \mathrm{MPa}$ could be obtained. For the series 1 specimens, the stress - crack opening relation was also determined (Fig. 6a), by analyzing the displacement field of the process zone through DIC image processing. In Fig. 6b, the longitudinal strain field for a given load as obtained from DIC is also reported, allowing to observe the extension of the crack process zone.

From direct tensile tests also the mortar elastic modulus as well as Poisson's coefficient were evaluated before cracking. This was possible through the strain measurements recorded by the longitudinal and transversal strain gauges placed in three specimens of the second series. The elastic modulus was determined from the initial branch slope of obtained stress-strain relations, resulting in an average value of $13.7 \mathrm{GPa}$. A mean value of Poisson's coefficient equal to 0.21 was determined, as the ratio between the transversal and the longitudinal strain.

\section{Three-point-bending tests}

In three-point-bending tests, the crack starts from the notch and gradually develops thanks to the bridging action of dispersed fibres, which allow the reaching of high values of crack opening (Figs. 7, 8). The evolution of crack path can be 
also analysed through DIC image elaboration in terms of horizontal strains, as shown in Fig. 8b, where is evident the localization at crack tip. From the analysis of the vertical displacement field, it is possible to compute the deflection $\delta$, removing rigid displacements at the supports, and so representing the specimen response in terms of load - midspan deflection (Fig. 9a). Fig. 9b also shows the experimental results in terms of load - CMOD.

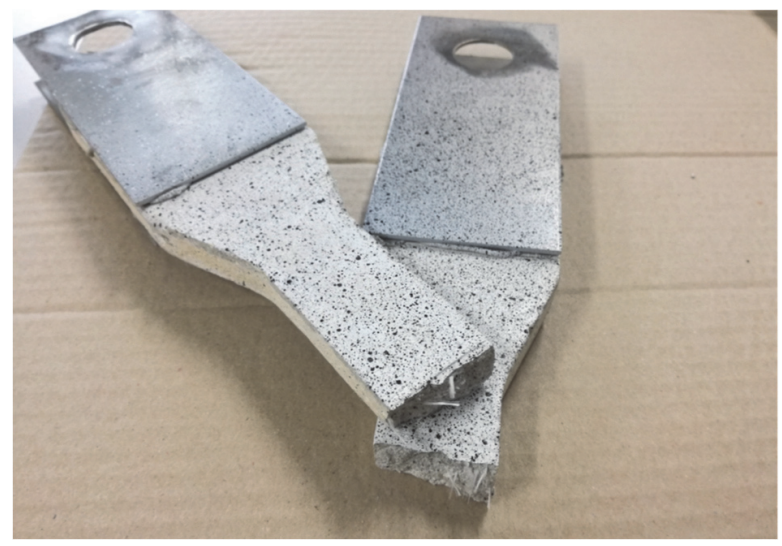

(a)

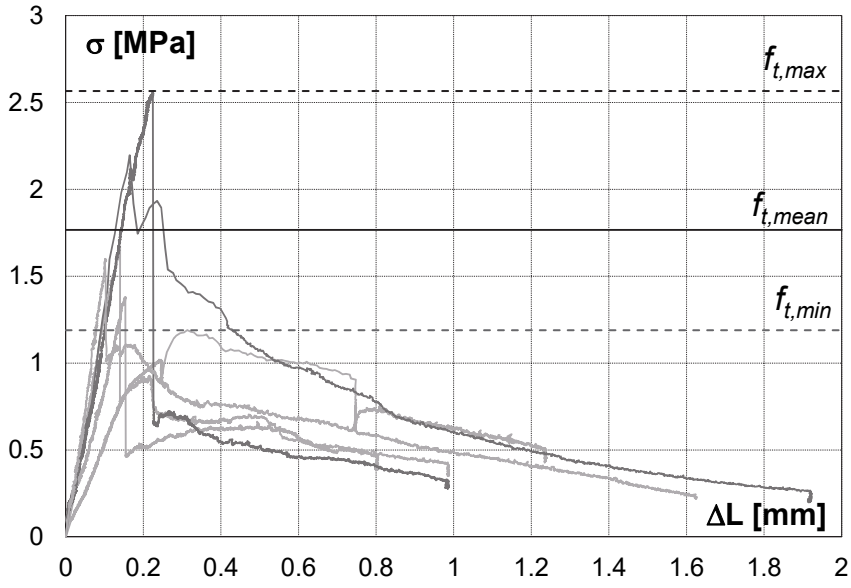

(b)

Figure 5: (a) View of the specimen at the end of the test: detail of fibers crossing crack surfaces; (b) stress vs. elongation $\Delta \mathrm{L}$ for series 1 specimens under direct tension.

\begin{tabular}{ccccc}
\hline Specimen ID & Width $[\mathrm{mm}]$ & Thickness $[\mathrm{mm}]$ & Peak Load $[\mathrm{kN}]$ & $\mathrm{f}_{\mathrm{t}, \mathrm{ax}}[\mathrm{MPa}]$ \\
T-1-1 & 30.06 & 14.64 & 0.523 & 1.19 \\
T-1-2 & 29.91 & 14.80 & 0.740 & 1.67 \\
T-1-3 & 30.12 & 15.05 & 0.995 & 2.20 \\
T-1-4 & 30.06 & 15.24 & 0.632 & 1.38 \\
T-1-5 & 29.91 & 14.60 & 1.119 & 2.57 \\
T-1-6 & 29.98 & 15.03 & 0.720 & 1.60 \\
& & & & $\mathbf{f}_{\text {t,ax,mean }}=\mathbf{1 . 7 7} \mathbf{~ M P a}$ \\
\hline
\end{tabular}

Table 1: Direct tension tests, $1^{\text {st }}$ series: cross section dimensions of the central part of the specimens, achieved peak load and corresponding axial tensile strength $\left(f_{t, a x}\right)$.

\begin{tabular}{ccccc}
\hline Specimen ID & Width $[\mathrm{mm}]$ & Thickness $[\mathrm{mm}]$ & Peak Load $[\mathrm{kN}]$ & $\mathrm{f}_{\text {t,ax }}[\mathrm{MPa}]$ \\
T-2-1 & 38.17 & 15.40 & 1.194 & 2.03 \\
T-2-2 & 30.19 & 14.92 & 0.979 & 2.18 \\
T-2-3 & 33.20 & 14.04 & 1.080 & 2.32 \\
T-2-4 & 29.27 & 14.60 & 0.860 & 2.01 \\
T-2-5 & 30.71 & 15.23 & 1.177 & 2.52 \\
T-2-6 & 30.18 & 14.24 & 0.527 & 1.23 \\
T-2-7 & 30.17 & 14.03 & 0.719 & 1.70 \\
T-2-8 & 29.77 & 14.34 & 0.975 & 2.28 \\
T-2-9 & 29.58 & 13.99 & 1.005 & 2.43 \\
& & & & $\mathbf{f}_{\text {t,ax,mean }}=\mathbf{2 . 0 8} \mathbf{~ M P a}$ \\
\hline
\end{tabular}

Table 2: Direct tension tests, $2^{\text {nd }}$ series: cross section dimensions of the central part of the specimens, achieved peak load and corresponding axial tensile strength $\left(\mathrm{f}_{\mathrm{t}, \mathrm{ax}}\right)$. 


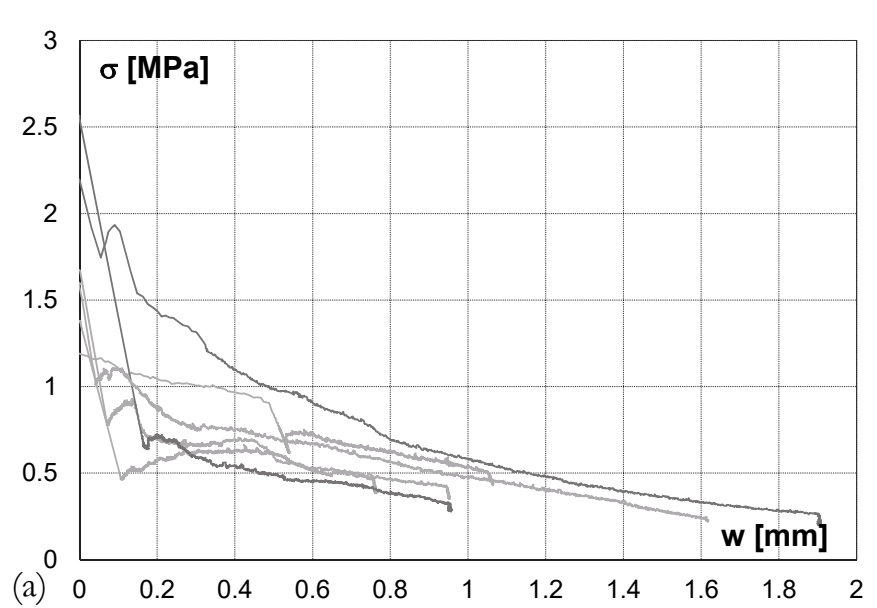

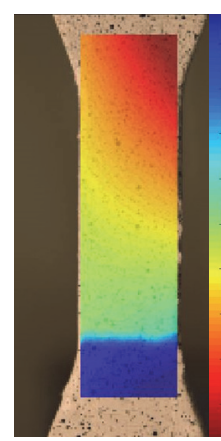

0.20

$[\mathrm{mm}]$

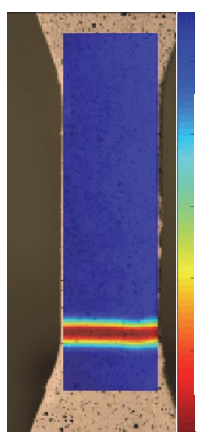

$\left[\mathrm{x} 10^{-3}\right]$

(b)

Figure 6: (a) Stress vs. crack opening w and (b) evaluation of the longitudinal displacement and longitudinal strain fields by means of DIC image processing, for series 1 specimens under direct tension.

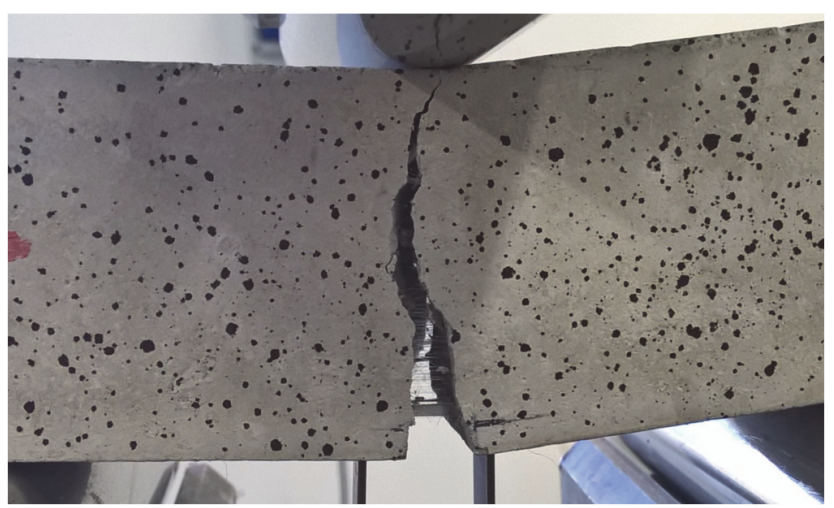

Figure 7: Bridging action of dispersed fibers during three-point-bending tests.

(a)
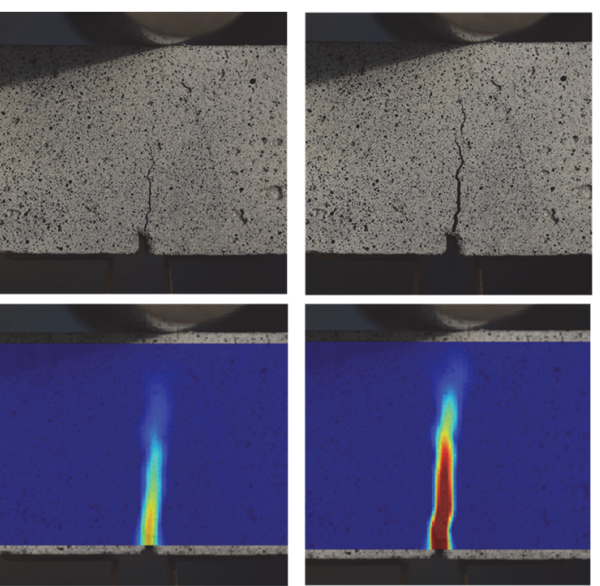
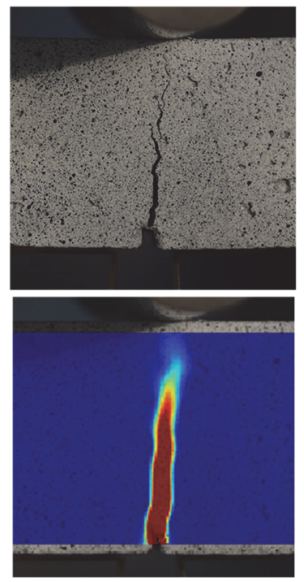
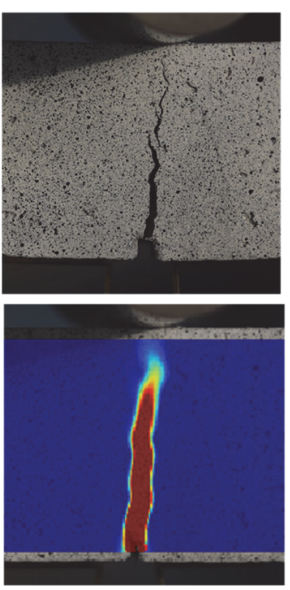

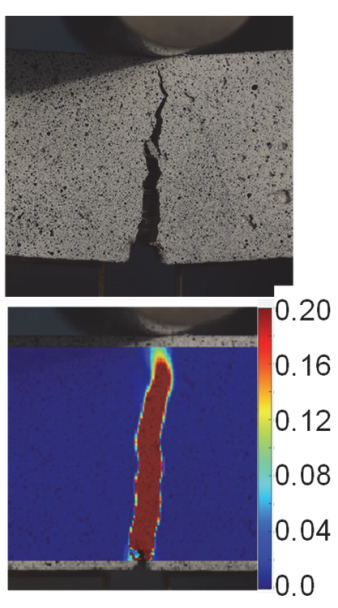

Figure 8: Specimen B-1-3 (a) crack development and (b) corresponding horizontal strain field around the notch from DIC.

\section{RESULT DISCUSSION}

$\mathrm{F}$

rom three-point-bending DIC results, it was also possible to assess the load corrisponding to the actual development of the first crack $\left(\mathrm{P}_{\mathrm{cr}}\right)$, which is lower then the peak load $\left(\mathrm{P}_{\max }\right)$, from which tensile flexural strenght $\mathrm{f}_{\mathrm{t}, \mathrm{fl}}$ is usually determined. From both the analysis of the horizontal displacements and strain fields across and over the notch 
obtained from DIC processing (see Fig. 8b), it was detected the step corresponding to cracking onset and the corresponding initial cracking load $\mathrm{P}_{\mathrm{cr}}$ was so identified and adopted to determine the axial tensile strenght $\left(\mathrm{f}_{\mathrm{t}, \mathrm{ax}}\right)$. The obtained values for the tested specimens are reported in Tab. 3. The ratio between the so determined mean values of axial and flexural tensile strength (equal to 2.33 and $4.22 \mathrm{MPa}$, respectively) is 0.55 . The same ratio obtained by considering the mean value of $\mathrm{f}_{\mathrm{t}, \mathrm{ax}}$ obtained from direct tension tests is 0.46 . As can be observed, these values are similar.

However, Tab. 3 shows that the values of $\mathrm{f}_{\mathrm{t}, \mathrm{ax}}$ from DIC are much more scattered, due to the uncertaintes in the determinatin of $\mathrm{P}_{\mathrm{cr}}$, which is strongly dependent on the frequency of digital image acquisition in relation to crack speed development. On the other hand, the test results obtained from beams under bending are much more reliable since they avoid the difficulties connected to the execution of direct tension tests.
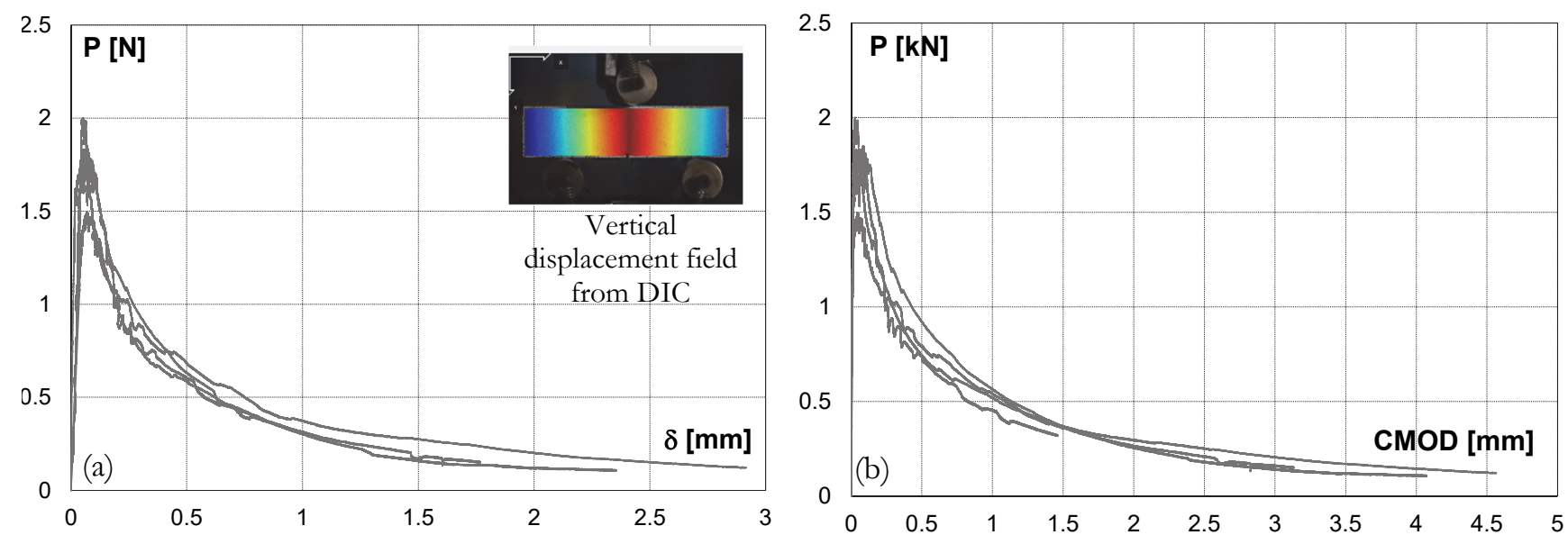

Figure 9: (a) Load vs. midspan deflection; (b) load vs. crack mouth opening displacement (CMOD), for series 2 specimens under bending.

\begin{tabular}{ccccccccc}
\hline Specimen & $\mathrm{b}[\mathrm{mm}]$ & $\mathrm{h}[\mathrm{mm}]$ & $\mathrm{d}[\mathrm{mm}]$ & $\mathrm{P}_{\max }[\mathrm{kN}]$ & $\mathrm{P}_{\mathrm{cr}}[\mathrm{kN}]$ & $\mathrm{f}_{\mathrm{t}, \mathrm{fl}}[\mathrm{MPa}]$ & $\mathrm{f}_{\mathrm{t}, \mathrm{ax}}[\mathrm{MPa}]$ & $\mathrm{f}_{\mathrm{t}, \mathrm{ax}} / \mathrm{f}_{\mathrm{t}, \mathrm{fl}}$ \\
B-1-1 & 40.18 & 41.18 & 2.98 & 1.78 & 1.37 & 4.55 & 3.49 & 0.768 \\
B-1-2 & 40.87 & 41.08 & 3.01 & 1.30 & 0.76 & 3.30 & 1.92 & 0.580 \\
B-1-3 & 40.23 & 41.40 & 3.02 & 1.25 & 0.94 & 3.17 & 2.39 & 0.753 \\
B-2-1 & 41.70 & 40.10 & 3.00 & 1.50 & 0.26 & 3.91 & 0.68 & 0.175 \\
B-2-2 & 41.40 & 40.16 & 2.60 & 1.83 & 0.41 & 4.70 & 1.06 & 0.225 \\
B-2-3 & 41.00 & 40.20 & 2.52 & 2.00 & 1.35 & 5.15 & 3.47 & 0.673 \\
B-2-4 & 41.00 & 40.05 & 2.22 & 1.85 & 1.30 & 4.74 & 3.33 & 0.703 \\
\hline
\end{tabular}

Table 3: Specimens under three-point-bending: cross section dimensions $(\mathrm{b} \times \mathrm{h})$, notch depth $\mathrm{d}$, flexural $\left(\mathrm{f}_{\mathrm{t}, \mathrm{fl}}\right)$ and axial $\left(\mathrm{f}_{\mathrm{t}, \mathrm{ax}}\right)$ tensile strength from peak load $\left(\mathrm{P}_{\max }\right)$ and from initial cracking load $\left(\mathrm{P}_{\mathrm{cr}}\right)$.

The obtained results can be compared with the relation proposed by MC2010 [8] for normal strength concrete, where the mean values of axial and flexural tensile strength are related by the coefficient $\alpha_{f}$, which is dependent on the beam depth $h_{b}$ through the expression:

$$
\alpha_{f l}=\left(0.06 b_{b}^{0.7}\right) /\left(1+0.06 b_{b}^{0.7}\right)
$$

By substituiting in Eq. (1) the actual beam depth $(=40 \mathrm{~mm})$ a $\alpha_{f l}$ coeffiecient equal to 0.44 can be obtained, so confirming that the correlation usually adopted for concrete can be extended also for this kind of cementitious matrix.

\section{CONCLUSIONS}

I $\mathrm{n}$ this work the behavior of fiber-reinforced mortar for FRCM composites is experimentally investigated, by comparing direct tensile and three-point-bending tests. Displacement and strain fields have been measured by means of DIC. Direct tensile test originally proposed for HPFRCC seems promising also for cementitious mortar, even if it requires 
special cares to avoid bending, scattered results and anomalous crack formation. Three-point-bending test execution is easier and allows providing less dispersed results in terms of flexural tensile strength. However, the determination of tensile axial strength requires to observe the actual crack onset. This is possible through DIC technique, even if some uncertainties in the results arise from the same DIC setup (such as image resolution and frequency of acquisition, etc.). A correlation factor between tensile strengths is herein proposed. This factor could be used by designers to determine the axial tensile strength from more simple three-point-bending tests. Obtained results are promising also for the calibration of a tension softening law for mortar. This is particularly appealing for the numerical modelling of these composite materials, which requires an accurate description of the post-cracking regime.

\section{REFERENCES}

[1] Pellegrino, C., Sena-Cruz J. eds., (2016). Fiber Reinforced Composites with Cementitious (Inorganic) Matrix, In: Design Procedures for the Use of Composites in Strengthening of Reinforced Concrete Structures, State-of-the-art report RILEM TC 234-DUC, Netherlands, Springer, pp. 349-392. DOI: 10.1007/978-94-017-7336-2_9.

[2] Carozzi, F.G., Poggi, C. (2015). Mechanical properties and debonding strength of Fabric Reinforced Cementitious Matrix (FRCM) systems for masonry strengthening, Compos. Part B-Eng., 70, pp. 215-230.

DOI: 10.1016/j.compositesb.2014.10.056

[3] D'Antino, T., Carloni, C., Sneed, L.H., Pellegrino, C. (2014). Matrix-fiber bond behaviour in PBO FRCM composites: A fracture mechanics approach, Eng. Frac. Mech., 117, pp. 94-111, DOI: 10.1016/j.engfracmech.2014.01.011.

[4] D'Ambrisi, A., Focacci, F. (2011). Flexural Strengthening of RC Beams with Cement-Based Composites, ASCE J. Compos. Constr, 15, pp. 707-720. DOI: 10.1061/(ASCE)CC.1943-5614.0000218.

[5] Ombres, L. (2011). Flexural analysis of reinforced concrete beams strengthened with a cement based high strength composite material, Compos. Struct., 94, pp. 143-155. DOI: 10.1016/j.compstruct.2011.07.008.

[6] Rosati, G., Natali Sora, M.P. (2001). Direct tensile tests on concretelike materials: structural and constitutive behaviors, J. Eng. Mech., 127, pp. 364-371. DOI: 10.1061/(ASCE)0733-9399(2001)127:4(364).

[7] Cattaneo, S., Rosati, G. (1999). Effect of different boundary conditions in direct tensile tests: experimental results, Mag. Concr. Res., 51, pp. 365-374. DOI: 10.1680/macr.1999.51.5.365.

[8] CEB-FIP Bulletin No.65 (2012), Model Code 2010, Final draft - vol. 1. Lausanne: International Federation for Structural Concrete.

[9] Carloni, C., D’Antino, T., Sneed L.H., Pellegrino, C. (2018). Three-Dimensional Numerical Modeling of Single-Lap Direct Shear Tests of FRC-Concrete Joints Using a Cohesive Damage Contact Approach, ASCE J. Compos. Constr., 22. DOI: $10.1061 /(A S C E) C C: 1943-5614.0000827$.

[10] Bernardi P., Ferretti D., Leurini F., Michelini E. (2016). A non-linear constitutive relation for the analysis of FRCM elements. Proc. Struct. Integr., 2, pp. 2674-2681. DOI: 10.1016/j.prostr.2016.06.334.

[11]Japan Society of Civil Engineers (2008), Recommendations for Design and Construction of High Performance Fiber Reinforced Cement Composites with Multiple Fine Cracks (HPFRCC ), Concr. Eng. Ser. 82: Testing Method 6-10.

[12] EN 1015-11: 1999/A1: 2006 (2006), Methods of test for mortar for masonry - Part 11. Determination of flexural and compressive strength of hardened mortar.

[13] Tekieli, M., De Santis, S., de Felice, G., Kwiecien, A., Roscini, F. (2017). Application of Digital Image Correlation to composite reinforcements, Compos. Struct., 160, pp. 670-688. DOI: 10.1016/j.compstruct.2016.10.096.

[14] Blaber, J., Adair, B., Antoniou, A. (2016). Ncorr: open-source 2D digital image correlation matlab software, Exp. Mech., 55, pp. 1105-1122. DOI: 10.1007/s11340-015-0009-1. 